\title{
Las encuadernaciones mudéjares de los Morales de san Gregorio de la Biblioteca Nacional de España
}

\author{
Antonio Carpallo Bautista* \\ José Luis Gonzalo Sánchez-Molero*
}

Artículo recibido:

10 de mayo de 2021

Artículo aceptado:

18 de octubre de 2021

Artículo de investigación

\section{Resumen}

Las bibliotecas españolas, europeas y latinoamericanas contienen en su fondo antiguo numerosas encuadernaciones de influencia árabe no estudiadas; entre estas instituciones tenemos las bibliotecas nacionales de España, México y Colombia. En este trabajo se realiza un estudio sobre las encuadernaciones mudéjares de los Morales sobre el libro de Job de san Gregorio, procedentes de la Biblioteca de la Casa de Alba. Se lleva a cabo un análisis de la estructura decorativa, así como de los elementos, utensilios y técnicas ornamentales. El análisis de los datos nos indica que fueron realizadas en el mismo taller y en la misma época, y fueron adquiridas por la Biblioteca Nacional de España a finales de 2017.

* Facultad de Ciencias de la Documentación, Universidad Complutense de Madrid, España acarpall@ucm.es jlgonz01@pdi.ucm.es

INVESTIGACIÓN BIBLIOTECOLÓGICA, vol. 36, núm. 90, enero/marzo, 2022, México, ISSN: 2448-8321 pp. 101-118 
Palabras clave: Encuadernaciones Mudéjares; Biblioteca de la Casa de Alba; Biblioteca Nacional de España

The Mudéjar bindings of the Morales by Saint Gregory of the National Library of Spain

Antonio Carpallo Bautista and José Luis Gonzalo Sánchez-Molero

\section{Abstract}

Spanish, European and Latin American libraries contain in their antique collections numerous bindings of Arabic influence that have not been studied, as is the case of such important libraries as the National Libraries of Spain, Mexico and Colombia, among others. This paper studies the Mudéjar bindings of the Morals on the Book of Job by Saint Gregory, from the Biblioteca de la Casa de Alba. An analysis is carried out of the decorative structure, as well as of the elements, tools and ornamental techniques. The analysis of the data indicates that they were made in the same workshop and at the same time, and were acquired by the National Library of Spain at the end of 2017.

Keywords: Mudéjar Bindings; House of Alba Library; National Library of Spain

\section{INTRODUCCIÓN}

Z1 Ducado de Alba de Tormes, más conocido como Ducado de Alba o CaEsa Ducal de Alba, es uno de los títulos nobiliarios más relevantes de España, otorgado por el rey Enrique IV de Castilla en 1472 a García Álvarez de Toledo y Carrillo de Toledo (c. 1424-1488), I Duque de Alba. La Biblioteca de la Casa de Alba conserva el fondo librario y documental procedente del legado de los Duques de Alba y de las casas nobiliarias vinculadas desde el siglo XIV, siendo uno de los primeros impulsores el II Duque de Alba, Fadrique Álvarez de Toledo (1458-1531), que recibió la Grandeza de España en 1520 por Carlos V, constituyendo para él personalmente y para su ducado un mayor reconocimiento en la nobleza española, ya que se encuentra en tercer lugar de importancia después del Príncipe de Asturias y del Infante de España. 
Desde el último cuarto del siglo XV, siendo II Duque de Alba Fadrique Álvarez de Toledo (1458-1531), se ha conservado en la Biblioteca de la Casa de Alba (ubicada desde el siglo XVIII en el Palacio de Liria, en Madrid) una traducción en cuatro volúmenes de los Morales sobre el libro de Job de san Gregorio, de Pedro López de Ayala, Canciller Mayor de Castilla, ricamente decorados con miniaturas e iniciales ornamentadas con motivos vegetales y geométricos.

Estos cuatro volúmenes, junto a la obra Debate de Elena y María, fueron adquiridos por la Biblioteca Nacional de España a finales de 2017, ${ }^{1}$ completando así la colección de traducciones de los Morales que ya tenía (BNE Mss./10136-10138, BNE Mss./12734-12736). Además, en la Biblioteca de la Casa de Alba se conserva una interesante colección de códices bajomedievales que, si bien son menos conocidos que la famosa Biblia en romance versionada para el comendador don Luis de Guzmán, han merecido el interés de los especialistas por su importancia como testimonios de la lectura del canon bíblico en la España medieval.

Resulta difícil trazar su evolución histórica, ya que en 1936 se perdieron más de la mitad de sus fondos, y no se conservaron catálogos bibliográficos. La destrucción del palacio significó una gran pérdida para la biblioteca, paliada en parte con la compra que el duque Jacobo Fitz James hizo de la magnífica biblioteca de Vicente Castañeda, secretario de la Real Academia de la Historia, que destacaba por sus cuidadas encuadernaciones y por contener un fondo muy rico de obras de temática valenciana. En cualquier caso, resulta evidente que la biblioteca ducal (como un conjunto formal y diferenciado) debió empezar a formarse como tal a principios del siglo XVIII, desde el momento en que los Fitz James Stuart, duques de Liria y Xérica, decidieron asentarse definitivamente en Madrid, con fondos bibliográficos que se fueron adquiriendo y también con aportaciones de algunas de las casas nobiliarias que mediante matrimonio fueron incorporándose sucesivamente a la Casa. No fue, sin embargo, hasta fines del siglo XIX cuando sus fondos empezaron a ser estudiados y catalogados, gracias a la iniciativa de María del Rosario Falcó, duquesa consorte de Alba (1854-1904), de Antonio Paz y Melia (1842-1927) y de Jacobo Fitz-James Stuart y Falcó, XVII duque de Alba

1 La propuesta de venta de las obras fue realizada por la Fundación Casa de Alba. En ese momento, el Director del Departamento de Manuscritos, Incunables y Raros, y la Jefa de Servicio de Manuscritos e Incunables visitaron el Palacio de Liria en junio de 2017 para comprobar el interés de los dos manuscritos que finalmente se compraron. La revisión directa de los originales confirmó el valor e interés de ambas piezas. Tras la redacción de los informes pertinentes, la dirección de la Biblioteca Nacional de España, junto al Servicio de Valoración de la propia biblioteca, fueron quienes se ocuparon de toda la tramitación económica. Las obras ya pertenecen a la Biblioteca Nacional de España, están catalogadas y digitalizadas, y se pueden consultar en la Sala Cervantes y en la Biblioteca Digital Hispánica. 
(1878-1953). De esta manera se empezaron a conocer algunos de sus volúmenes más valiosos, entre los que para esta ocasión se han seleccionado algunos de los códices que conservan sus encuadernaciones mudéjares originales. Nos referimos a los siguientes:

- John de Hoveden. Espéculo de los legos. Traductor desconocido al castellano. "Espejo de Legos de letra antigua sobre las virtudes y vicios y otros puntos religiosos" (título según cartela pegada en el interior de la primera tapa). Fue copiado por Gómez González. Quizás el arcediano de Cuéllar (colofón fechado en 1409). Signatura: Alba. Ms. 9.²

- Gregorio I, papa. Morales (Moralia in Job). Obra copiada hacia 1450. Signatura: Alba. Ms. 63, 63bis, 71 y $64 .^{3}$

Como estudiara Gemma Avenoza, esta colección de manuscritos contiene una copia completa de los Morales sobre el libro de Job, traducida al castellano por el Canciller Pedro López de Ayala ${ }^{4}$ (Avenoza, 2010; 2014; 2015). En los ejemplares de la Biblioteca Nacional de España, el códice con signatura BNE Res/292 se abre con una imagen a toda página de la presentación de la traducción al papa Gregorio Magno por su traductor Ayala. Este manuscrito, como los que contienen las signaturas BNE Res/294 y BNE Res/295, son acéfalos y han perdido el primer folio del texto, lo que dificultó su identificación y catalogación en la biblioteca de los duques de Alba, razón por la que colocaron en diferentes ubicaciones. Estos códices son ejemplares muy cercanos en cuanto a su copia a la colección de los Morales, existente hoy en la Biblioteca Nacional de España (BNE Mss./10136-10138). Se considera, por tanto, que por su semejanza en cuestiones codicológicas, textuales y paleográficas, la copia de ambos grupos de manuscritos se realizó en un mismo taller y con poco tiempo de diferencia (Fuentes y Avenoza, 2012-2013). En la autorizada opinión de Avenoza (2015: 275):

2 Referencias codicológicas en la web de Philobiblon: BETA manid 4837. Fecha de consulta: 8 de mayo de 2021. http://bancroft.berkeley.edu/philobiblon/

3 En la actualidad estos códices tienen las siguientes signaturas de la Biblioteca Nacional de España: Alba. Ms. 63: BNE Res/292; Alba. 63bis: BNE Res/294; Alba. 71: BNE Res/293; Alba. 64: BNE Res/295.

4 Las referencias codicológicas de estos cuatro códices pueden consultarse en la web de Philobiblon: BETA manid 4815, 4816, 5220 y 4817. Fecha de consulta: 8 de mayo de 2021. http:// bancroft.berkeley.edu/philobiblon/ 
La comparación entre estos grupos de manuscritos (BN y Alba- traducción de Ayala- y Escorial b-II-10 y b-II-11 -traducción anónima-) nos lleva a proponer que todos ellos fueron copiados en un mismo scriptorium, que debió de ser un centro relativamente importante, tratándose en todos los casos de ejemplares realizados sobre buen pergamino. Esto nos lleva a sugerir que se trataba de un scriptorium especializado en copiar Morales de Gregorio Magno.

Sobre el origen de estas copias de taller se interrogaban hace poco tiempo la misma autora y Coderch. Los ejemplares de Alba parece que pudieron pertenecer a Fernán Álvarez de Toledo y Zapata, señor de Cedillo, pues el escudo de armas que figura en uno de los volúmenes fue identificado como perteneciente a un miembro de este linaje por José María de Francisco Olmos (Avenoza, 2015); el juego de la Biblioteca Nacional de España (BNE Mss./10136-10138), en cambio, fue copiado sin duda para el marqués de Santillana, don Î́nigo López de Mendoza (1398-1458).

- Autor desconocido. [Opúsculos de espiritualidad]. Copiado c. 1500. Signatura: Alba. Ms. 79. ${ }^{5}$

- Autor desconocido. [Exposición o declaración de la Biblia]. Obra copiada hacia 1472-1500. Signatura: Alba. Ms. 100. Ha sido estudiado también por Gemma Avenoza (2008: 59-60). ${ }^{6}$

Todos los manuscritos citados proceden de la biblioteca de Fadrique Álvarez de Toledo (1460-1531), II duque de Alba, ya que aparecen en el inventario de sus bienes realizado en 1531, a su muerte, transcrito y analizado recientemente por Álvaro Bustos Táuler y Rebeca Sanmartín Bastida (2016). ${ }^{7}$ En este inventario se localizan los cuatro ejemplares actuales de los Morales (BNE Res/292-295), que se corresponden con estas entradas:

(3). Otro libro de unas tablas coloradas con unos tejillos guarneçidos de plata que dize el Dezenio libro de los Morales de San Gregorio.

(4). Otro libro en pergamino que dize diez e ocho libros de los Morales de San Gregorio sobre libro de Jo(b) con su guarniçion de plata que le falta donde prende las manecillas.

5 Referencias codicológicas en la web de Philobiblon: BETA manid 4879. Fecha de consulta: 8 de mayo de 2021. http://bancroft.berkeley.edu/philobiblon/

6 Referencias codicológicas en la web de Philobiblon: BETA manid 4839. Fecha de consulta: 8 de mayo de 2021. http://bancroft.berkeley.edu/philobiblon/

7 Archivo Ducal de Alba (ADA), en Palacio de Liria, en la Caja 23, nº 29. 
Y al final del inventario:

(154). Otro libro de los morales de San Gregorio con unos texillos y la guarniçion de plata.

(155). Otro libro de la mesma manera de los Morales.

Las encuadernaciones mudéjares actuales parecen ser las mismas descritas, pues son de color marrón rojizo (quizás a causa del tiempo y la acumulación de suciedad se ha ido oscureciendo el rojo original) y tienen restos de apliques de plata. Como ya hemos adelantado, por la presencia de un escudo iluminado en uno de estos volúmenes se deduce que su dueño inicial pudo ser Fernán Álvarez de Toledo, señor de Cedillo (c. 1435-c. 1508), que, a pesar de compartir apellido con el Duque de Alba, no tuvo relación familiar con éste, quien quizás se hiciera con estos ejemplares en almoneda tras su muerte. Figura también en este documento, con el número 163, "Otro libro de los Morales de San Gregorio en romançe” (que creemos una edición impresa), y "(172). Otro libro de los Morales de San Jerónimo", sin relación con los anteriores.

El manuscrito de la Exposición o declaración de la Biblia (Alba. Ms. 100) se corresponde con esta entrada del inventario: "(124). Otro libro mediano que dize tratado que hizo el maestrescuela de Salamanca". No se le da título alguno en 1531, pero el íncipit de este códice comienza así (Fol. 1r):

[M]uy virtuoso e muy discreto señor el maestre escuela de salamanca me encomiendo en vuestra merçed de la qual rrescebi vna letra e ella asaz en si rrepresentaua de la entendida e estudiosa condiçion del escriuiente porque segun aristotiles en las eticas qualis vno quisque est talia loquitur et operatur e nuestro señor dixo a fluctibus [!] eorum conosçetur eos Et entre los frutos ...

Parece tratarse de Gutierre Álvarez de Toledo, maestrescuela de Salamanca y obispo de Plasencia († 1508), hermano del propio duque don Fadrique, a quien debió llegar entonces, adquiriéndolo en la almoneda de este prelado por entonces, tras su muerte.

El ejemplar del Espejo de Legos (Alba. Ms. 9) coincide claramente con esta entrada del inventario de 1531: "(1). Un libro con unas tablas coloradas que dize en la una Espejo de los legos". No se describe la encuadernación como de estilo mudéjar, término no acuñado entonces (sí aparecerá el de "pie de moro", solo tres décadas más tarde) (Gonzalo Sánchez-Molero, 2013). El color, sin embargo, sí se corresponde con el del cuero de las tablas de este manuscrito en la actualidad, hoy muy oscurecido por el paso del tiempo y la acumulación de suciedad. Hay muchísimas notas marginales en latín con una letra 
cursiva distinta al copista; además, hay numerosas correcciones entre líneas, que aumentan hacia el final. No hemos localizado, en cambio, los anónimos Opúsculos de espiritualidad (Alba. Ms. 79) en el citado inventario de los libros del duque de Alba. Aunque no parece motivo suficiente para establecer una clara coincidencia, quizás pueda identificarse con el descrito vagamente como "Otro libro viejo de mano que dize tratado de la pasión prólogo" ( $n^{\circ} 148$ del inventario), pues en el texto se advierte: "Para mejor pensar en la pasión de Nuestro Redentor, cuya memoria continua es muy provechosa, es bueno partirla en muchas partes, y un día pensar en una parte della y otro día en otra parte. Espeçialmente se puede dividir en quince partes".

En la tapa posterior las dos ruedas cambian, la primera es de factura gótica y representa la letra "G" o "P". En la primera guarda se aprecia una nota, difícilmente legible, pues la tinta está desleída y porque hay un agujero de polilla en el nombre del propietario, pero que dice: "de los que se conpro $\operatorname{pr}[\ldots .$.$] de Maldonado".$

\section{Objetivos y metodología}

Sobre estas obras se han realizado diversos estudios, como los de Gemma Avenoza $^{8}$ y los de Luciano Serrano (1911), pero siempre desde la perspectiva codicológica, sin tener muy en cuenta la encuadernación, si es original o posterior, si hay alguna relación entre las encuadernaciones salidas de los mismos talleres o si son encuadernaciones distintas. Por lo tanto, el objetivo del trabajo es realizar un análisis de las encuadernaciones mudéjares de los Morales sobre el libro de Job, estudiando los materiales empleados, las técnicas constructivas, las estructuras y técnicas decorativas y el estado de conservación de cada uno de los volúmenes, y así determinar si fueron realizadas en la misma época y por los mismos artesanos.

La metodología seguida consistió, primeramente, en realizar un inventario de todas las encuadernaciones artísticas del Palacio de Liria, seleccionando a continuación estos cuatro volúmenes mudéjares, estudiando sus características constructivas y decorativas.

En cuanto a las encuadernaciones mudéjares en España, en los últimos años se han realizado estudios sobre ellas en diversas instituciones, como en la Biblioteca Nacional de España (BNE, 2013), Catedral de Toledo (Carpallo

8 Agradecer a la profesora Gemma Avenoza toda la ayuda prestada por compartir con nosotros todos sus trabajos sobre el tema. 
Bautista, 2012), Catedral de Segovia (Ruíz de Elvira, 1993), Universidad Complutense (Carpallo Bautista, 2009), Universidad de Valencia (2003), entre otras, lo que nos ha permitido identificar mucho mejor la tipología ornamental de estas encuadernaciones.

\section{ESTUDIO DE LAS ENCUADERNACIONES}

Las encuadernaciones de estilo mudéjar, también llamado hispano-árabe, se llevaron a cabo en la península ibérica entre el siglo XIV y primeras décadas del siglo XVI, teniendo su mayor auge en la segunda mitad del siglo XV, confeccionadas en su mayoría por artesanos judíos. Muy posiblemente es el estilo más característico de la encuadernación española en la historia de la encuadernación, creándose una tipología de estructuras decorativas como las denominadas de lacerías (salmantinas, toledanas y catalán-aragonesa), de bandas rectangulares, de rectángulo partido y de bandas oblicuas, además de mezclarse con otras estructuras y motivos ornamentales de estilos como el gótico, el renacentistas y el plateresco.

Las cuatro encuadernaciones con elementos artísticos y originales de los Morales sobre el libro de Job de la Biblioteca Nacional de España coinciden en muchos de los materiales utilizados en su elaboración, muy usuales en las encuadernaciones mudéjares de la época, como por ejemplo la piel rojiza de cabra, las tablas de madera, la estructura decorativa de lacerías en sus diferentes versiones y el empleo de numerosos hierros sueltos como bastoncillos curvos y rectos cordiformes. En todas encontramos que las tapas son de madera, lo que ofrece una mayor consistencia a la encuadernación y la posibilidad de utilizar broches y bollones de metal; el material de recubrimiento de las tapas y lomo es similar, piel de cabra de color rojizo; los nervios son de piel curtida al alumbre, al igual que el alma de las cabezadas y las guardas de pergamino.

En cuanto a la estructura constructiva, todos los ejemplares tienen sus tapas engarzadas al cuerpo del libro mediante varios nervios (tres o cuatro), algunos sencillos y otros hendidos, aunque las cuatro estructuras coinciden en la costura a punto seguido; también en que las cabezadas están unidas al lomo y a las tapas.

En las encuadernaciones adquiridas de la Biblioteca de la Casa de Alba por la Biblioteca Nacional de España (sig. BNE Res/292-295) la decoración de las cabezadas y de los cortes, así como el empleo de pergamino en las guardas, refuerzos de tela en el lomo y los broches de metal y piel, nos indican que fueron realizadas a finales del siglo XV en España y en el mismo taller. 
Estas primeras encuadernaciones que se estudian a continuación están dentro del grupo de las encuadernaciones mudéjares de lacerías, aunque las cuatro tienen diferentes estructuras decorativas y en la misma encuadernación la estructura no es simétrica, lo que nos apunta que eran encuadernaciones de lujo, en las que se dedicó mucho tiempo para su elaboración, junto a un gran trabajo de diseño y materiales de fabricación de primera calidad.

Las encuadernaciones llevan en la guarda anterior las etiquetas de los exlibris del Duque de Berwick y Alba, el primero con forma rectangular que contiene el escudo del duque de Alba y la leyenda alrededor "biblioteca / del duque / de berwick / y alba", el segundo con forma circular y la leyenda de la casa es: "TU IN EA, ET EGO PRO EA", que significa "Tú en ella y yo por ella", y el último con forma rectangular contiene la leyenda "El Duque de Berwick i Alba". En la cimera de las actuales armas aparece un ángel ataviado con tabardo que refleja las armas originales asociadas al título (Figura 1).
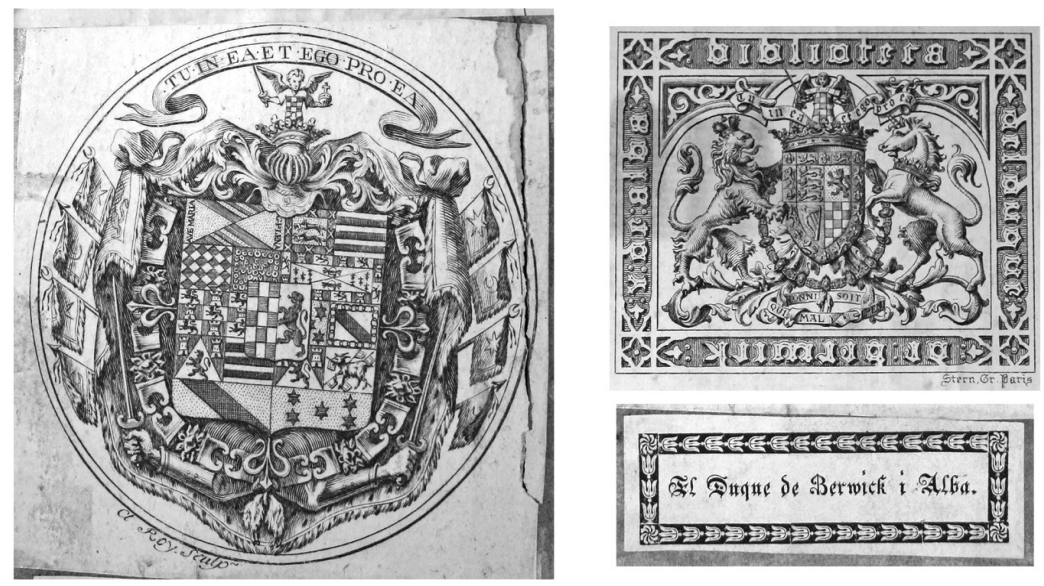

Figura 1. Exlibris (sig. BNE Res/295)

Este primer volumen contiene los Morales sobre el Libro de Job. Lib. I IX. La estructura decorativa de la tapa anterior de esta primera encuadernación (sig. BNE Res/292) la podemos encuadrar dentro del grupo de las encuadernaciones de lacerías con círculo central y la tapa posterior dentro del grupo de las que contienen motivo central, en este caso una estrella de ocho puntas (Figura 2). Sus dimensiones son 304 × 240 × 90 mm. Esta encuadernación formó parte de la exposición organizada por Francisco Hueso Rolland (1934: 187-188), incluyéndose en el catálogo una breve descripción y la lámina X. 

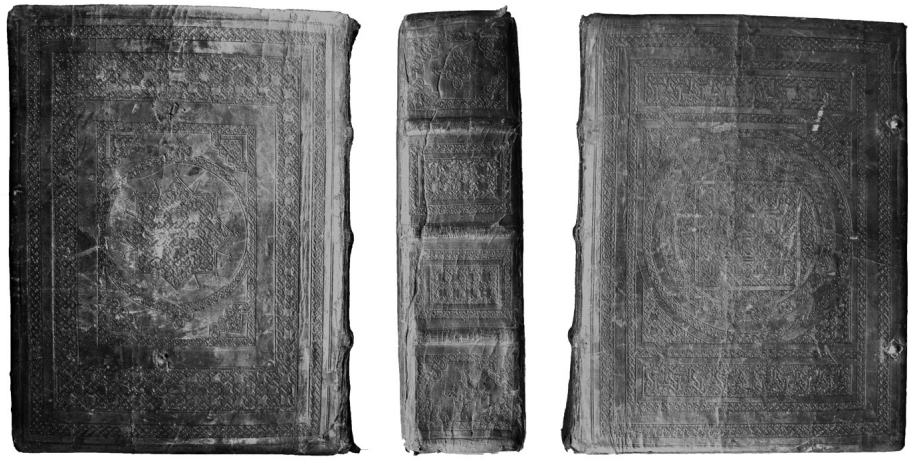

Figura 2. Tapa posterior, lomo y tapa anterior (sig. BNE Res/292)

La estructura decorativa no es simétrica. La decoración de ambas tapas contiene eses inclinadas y bastoncillos curvos y rectos formando rombos aspados; en la banda delantera de la tapa aparecen los restos de dos broches metálicos con forma de cuatro hojas. Los utensilios empleados han sido hierros sueltos y la técnica decorativa, el gofrado. Las cabezadas están decoradas con hilos de colores rojo y amarillo. En el centro de la tapa se muestran dos marcas donde estaban insertados los elementos metálicos de los cierres; es posible que el códice se cerrara por medio de cintas de terciopelo con dos broches metálicos a los extremos, decorados con motivos religiosos o heráldicos.

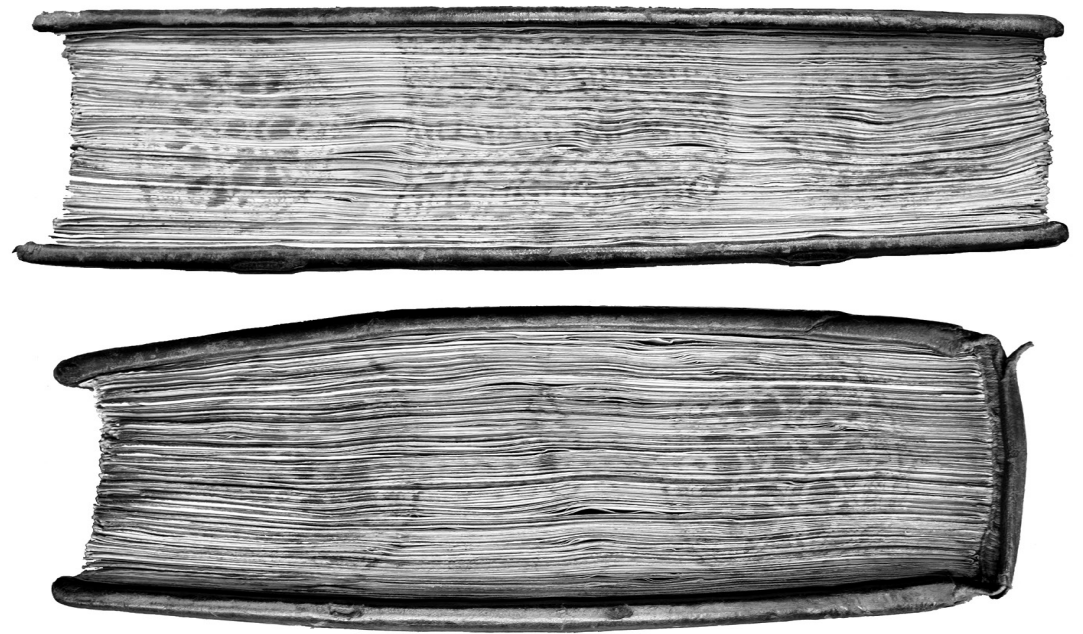

Figura 3. Cortes delantero e inferior (sig. BNE Res/292) 
Finalmente, los cortes superior e inferior contienen una composición policromada, de colores rojo y morado, con dos rosetones a los lados y una estrella de cuatro puntas en el centro; el corte delantero contiene dos rosetones en las esquinas y un rectángulo en el centro (Figura 3).

El segundo volumen contiene los Morales sobre el Libro de Job. Lib. X XVII. Esta segunda encuadernación (sig. BNE Res/293) también forma parte del grupo de lacerías y con el rectángulo partido, en el que encontramos en la tapa anterior dos círculos y en la tapa posterior dos estrellas de ocho puntas (Figura 4). Sus dimensiones son 300 x 222 × $75 \mathrm{~mm}$. El volumen lleva consigo otra etiqueta conmemorativa que indica que esta obra formó parte de la Exposición Histórica del Libro Español de 1952, haciendo el número 151 de la muestra (López Serrano y Tolsada, 1952: 35); además, formó parte de la exposición organizada por Francisco Hueso Rolland (1934: 188), incluyéndose en el catálogo una breve descripción y la lámina XI. También fue descrita por Avenoza (2014: 9) en 2014 dentro de un estudio codicológico sobre los Morales mucho más amplio.
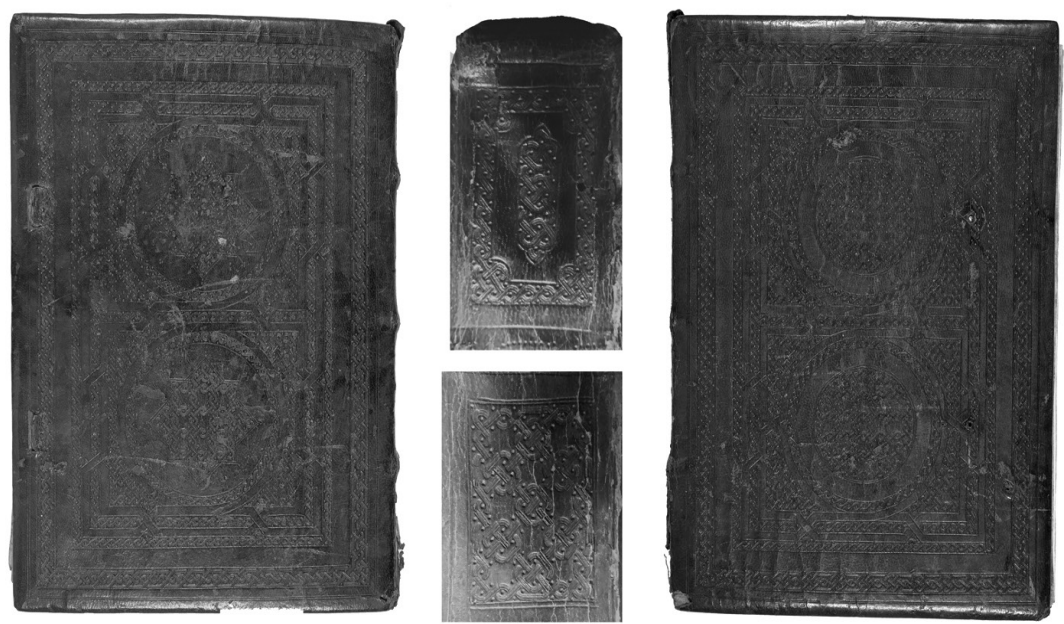

Figura 4. Tapa posterior, entrenervio superior y central y tapa anterior (sig. BNE Res/293)

La estructura decorativa es simétrica, aunque cambia la distribución de los cuadrados centrales. Su ornamentación contiene composiciones de bastoncillos curvos y rectos cordiformes que se entrecruzan y pequeños puntos eses que forman composiciones cuadradas; en la tapa central los dos círculos centrales se sustituyen por dos estrellas de ocho puntas. Los utensilios empleados han sido hierros sueltos y la técnica decorativa ha sido el gofrado. 

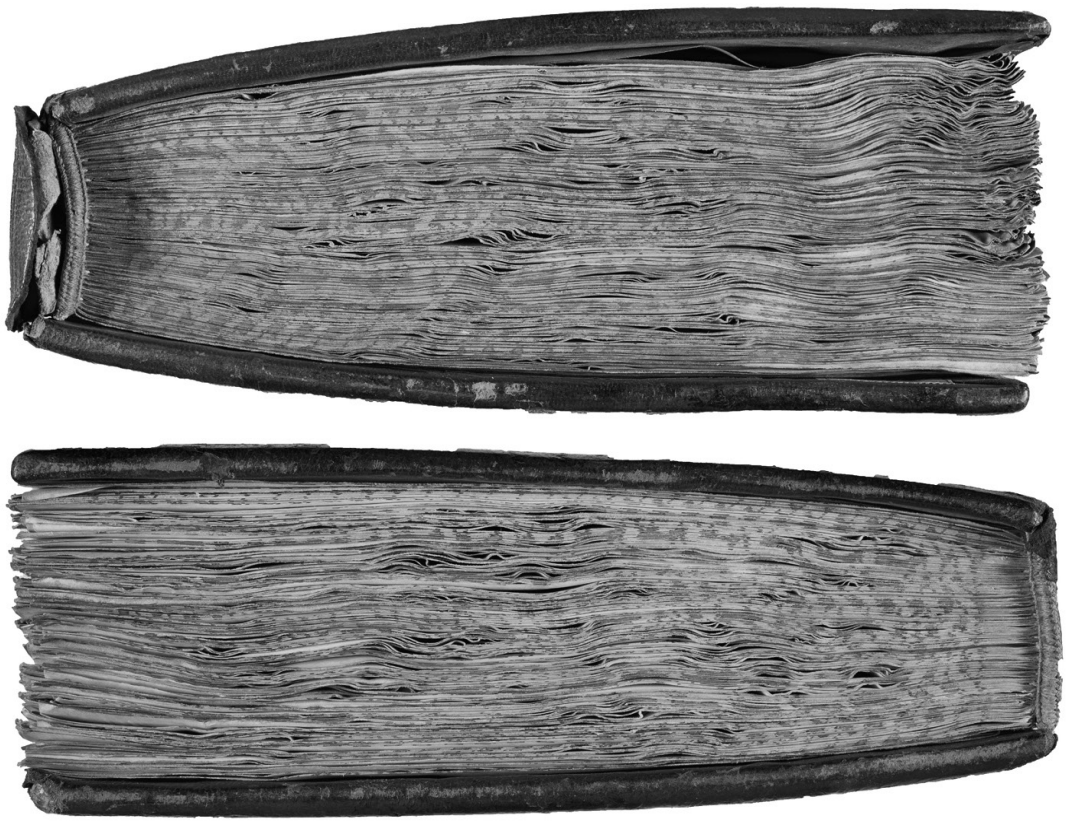

Figura 5. Corte superior e inferior (sig. BNE Res/293)

La oreja superior está decorada con dos hilos horizontales gofrados. En la banda vertical exterior de la tapa posterior aparecen dos restos de broches; en la tapa anterior aparece los agujeros de los cierres. Los cortes están decorados con una composición policromada, de colores rojo y morado, de hileras de pequeñas formas geométricas que se repiten. Las cabezadas están decoradas con el alternado de hilos de colores amarillo y verde (Figura 5).

El tercer volumen contiene los Morales sobre el Libro de Job. Lib. XVIII $X X V I$. La encuadernación que lo recubre es original de la época (sig. BNE Res/294) y sus dimensiones son 299 x 230 x 105 mm.

La estructura decorativa de este ejemplar la podemos encuadrar dentro del grupo de las encuadernaciones de lacerías con motivo central, en este caso una estrella de ocho puntas, aunque con diferente distribución (Figura 6). El análisis de la estructura constructiva nos revela que las tapas están engarzadas al cuerpo del libro mediante tres nervios, los dos de los extremos son sencillos y el central doble hendido, con un cosido a punto seguido. Las cabezadas, dobles con un pequeño cordoncillo superior y un nudo inferior, están unidas al cuerpo del libro y a las tapas. 

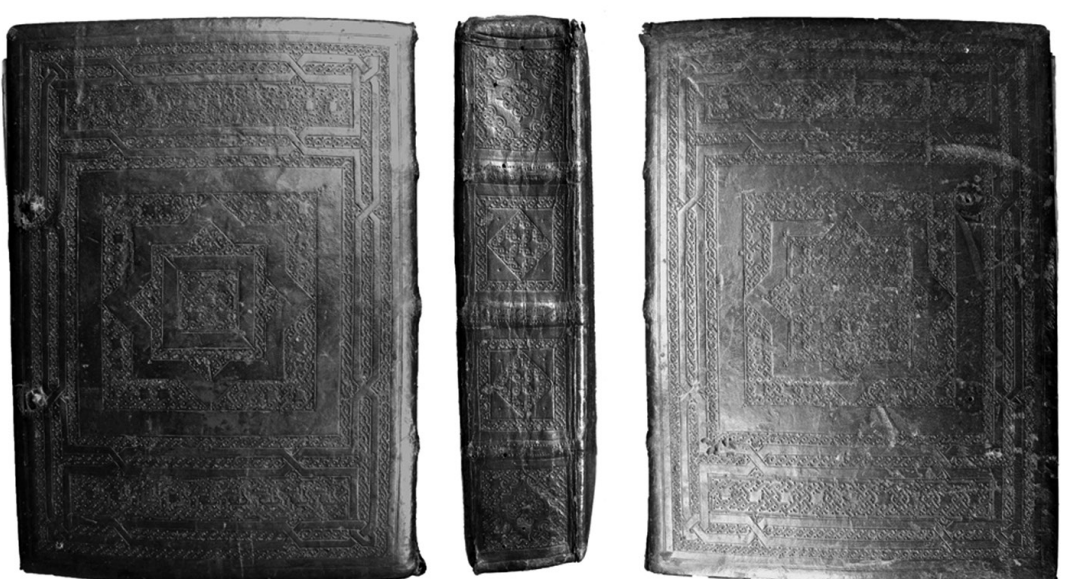

Figura 6. Tapa posterior, lomo y tapa anterior (sig. BNE Res/294)

La ornamentación de las tapas es simétrica; su estructura se basa en tres compartimentos y en el centro una estrella de ocho puntas con un entramado de lacerías; los espacios libres están cuajados de eses inclinadas cordiformes y pequeños puntos y con bastoncillos curvos y rectos cordiformes y pequeños puntos que dan lugar a rombos aspados. Los utensilios empleados han sido hierros sueltos y la técnica decorativa el gofrado, como en los ejemplares antes estudiados.

En los extremos del lomo se muestran orejas de piel decoradas con dos hilos horizontales. Toda la ornamentación del lomo se muestra gofrada. En la banda vertical exterior de la tapa posterior se presentan restos de dos broches, posiblemente de latón, con forma de tréboles de cuatro hojas. Los cortes están decorados con una composición dibujada. Las cabezadas se presentan decoradas con el alternado de hilos de colores rojo y amarillo (Figura 7).
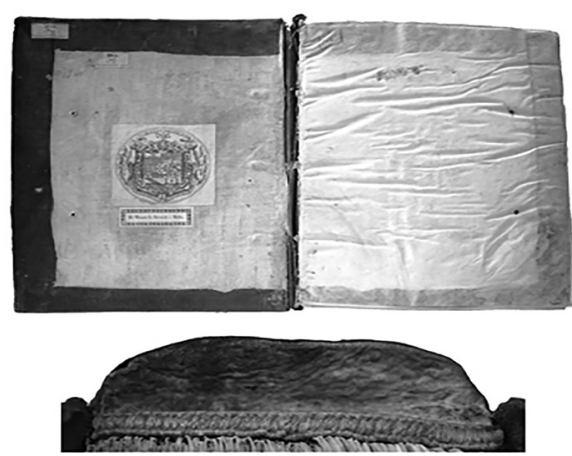

Figura 7. Guarda anterior, cabezada superior y oreja (sig. BNE Res/294) 
El cuarto volumen contiene los Morales sobre el Libro de Job. Lib. XXVII XXXV. Su encuadernación (sig. BNE Res/295) la podemos encuadrar dentro del grupo de las encuadernaciones de lacerías con rectángulo partido (Figura 8), siendo original de la época; sus dimensiones son 297 x 224 x $125 \mathrm{~mm}$. Esta encuadernación formó parte de la exposición organizada por Francisco Hueso Rolland (1934: 187), incluyéndose en el catálogo una breve descripción y la lámina X. Se puede observar en la guarda anterior las etiquetas de los exlibris del Duque de Berwick i Alba (Figura 10).
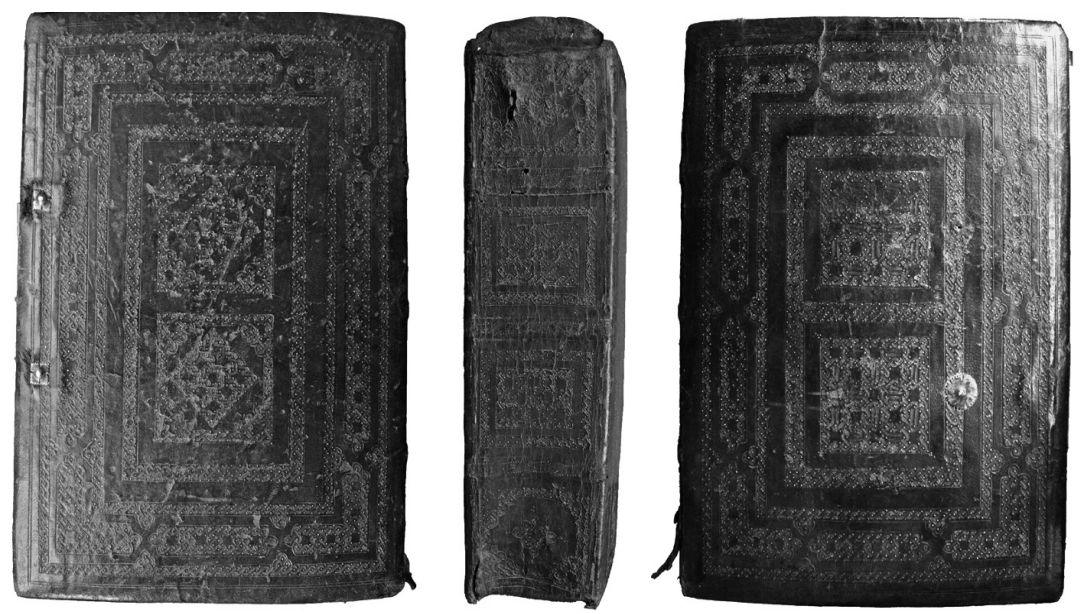

Figura 8. Tapa posterior, lomo y tapa anterior (sig. BNE Res/295)

La estructura decorativa es simétrica, aunque cambia la distribución de los cuadrados centrales, estando dentro del grupo de las encuadernaciones mudéjares de lacerías. Su estructura ornamental se basa en dos compartimentos cuadrados en la parte central de las tapas. La ornamentación contiene una estructura de cintas de dos hilos que se entrecruzan formando un entramado de lacerías; los espacios libres están cuajados de bastoncillos curvos y rectos cordiformes y pequeños puntos; en la parte central aparece un gran rectángulo que se divide en dos cuadrados que están ornamentados con bastoncillos curvos y rectos cordiformes y pequeños puntos que dan lugar a composiciones de rombos. Los utensilios empleados han sido hierros sueltos y la técnica decorativa ha sido el gofrado. 


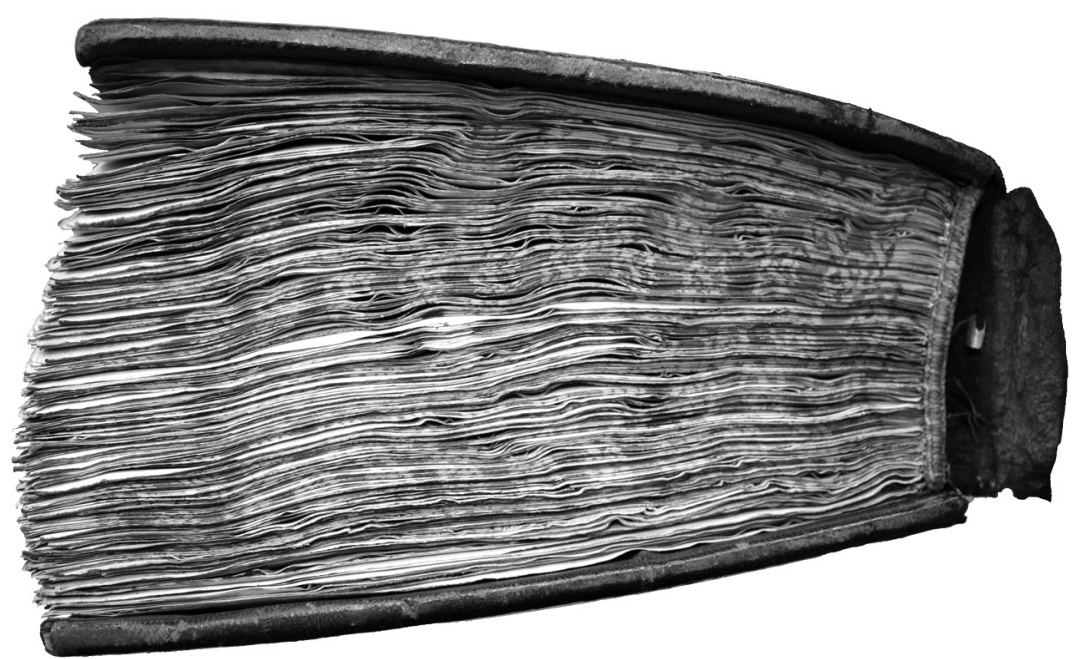

Figura 9. Corte superior y cabezada (sig. BNE Res/295)

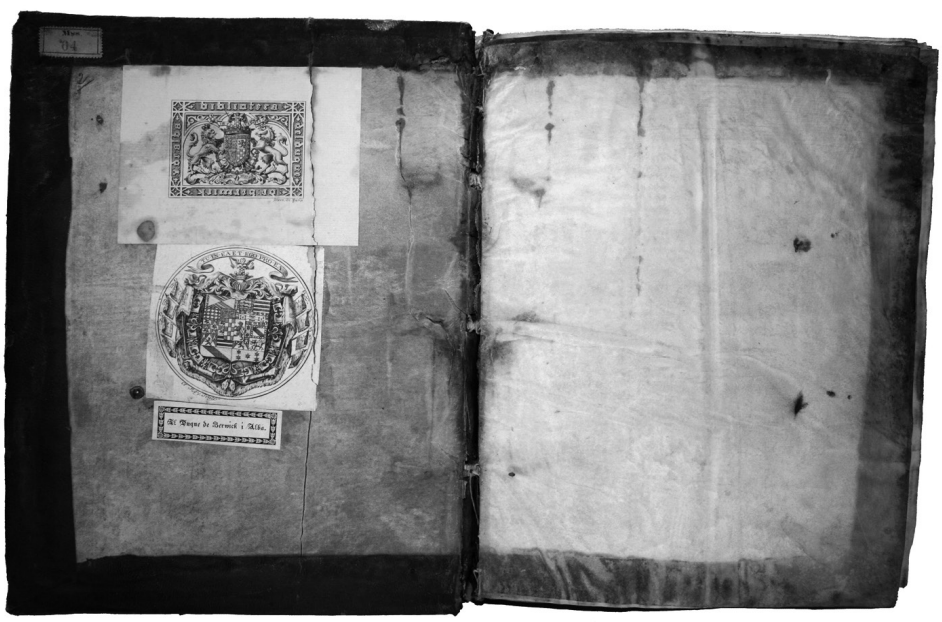

Figura 10. Guarda anterior con los exlibris (sig. BNE Res/295)

Para finalizar con el estudio de este volumen señalamos que en los extremos del lomo se muestran orejas de piel decoradas con dos hilos horizontales gofrados. En la banda vertical exterior de la tapa posterior aparecen dos broches con forma de tréboles de cuatro hojas, y restos de las cintas de terciopelo; en la tapa anterior observamos uno de los cierres con forma vegetal con siete hojas. Las cabezadas están decoradas con el alternado de hilos de colores rojo y amarillo. Los cortes están ornamentados con una composición policromada de colores rojo y azul (Figura 9). 
El análisis de las estructuras decorativas nos indica que las cuatro encuadernaciones contienen disposiciones distintas (sig. BNE Res/292-295), incluso estructuras diferentes en cada tapa, algo relativamente habitual en la decoración de encuadernaciones de lujo en los siglos XIV, XV y primeros del XVI. También el empleo de la piel de rojiza de cabra, las tablas de madera, la estructura decorativa de lacerías en sus diferentes versiones y el empleo de numerosos hierros sueltos, como bastoncillos curvos y rectos cordiformes, en las tapas y en los lomos, nos indican que son similares a los utilizados, sobre todo en la península ibérica, en lugares como Toledo, Salamanca, Zaragoza y Cataluña, no detectándose indicios de que las encuadernaciones pudieran ser italianas. Por tanto, el estudio y análisis de los materiales, elementos decorativos, estructuras constructivas y decorativas y ornamentación de los cortes de cada encuadernación, procedentes de la Biblioteca de la Casa de Alba (sig. BNE Res/292-295), muy posiblemente se realizaran a finales del siglo XV en España, y en el mismo taller.

Como hemos podido observar, son estructuras decorativas muy elaboradas, con un gran trabajo en su ejecución y diseño, realizadas por un taller con expertos encuadernadores, con ornamentación que varía en los cuatro volúmenes, en cada una de las tapas y también en los lomos. Encontramos estructuras decorativas de lacerías de tipo toledano, con círculo central en la tapa anterior y estrella de ocho puntas en la tapa posterior (sig. BNE Res/292) junto a otro volumen con una gran estrella de ocho puntas en el centro, cuajada completamente de pequeños bastoncillos curvos y rectos en el centro en la tapa anterior, y un cuadrado dentro de la estrella de ocho puntas en la tapa posterior (sig. BNE Res/294). La disposición ornamental de los otros dos volúmenes es diferente a estos anteriores, también de lacerías, pero con el rectángulo partido formando dos cuadrados, donde encontramos en la tapa anterior un cuadrado cuajado de bastoncillos rectos y curvos con pequeños cuadrados libres de decoración y en la tapa posterior rombos con esos mismos bastoncillos rectos y curvos formando pequeños cuadrados (sig. BNE Res/295), mientras que en el otro volumen la tapa anterior está ornamentada con dos círculos cuajados en su interior con bastoncillos rectos y curvos formando pequeños rectángulos y en la tapa posterior dos grandes círculos, cada uno con una estrella de ocho puntas en su interior cuajada de bastoncillos rectos y curvos formando pequeños rectángulos (sig. BNE Res/293).

Como conclusión final, la uniformidad en la encuadernación de estos cuatro códices, la misma tipología de hierros sueltos y sus variantes en la estructura decorativa, nos permite conocer mejor la tipología de encuadernaciones 
mudéjares que disponemos en diferentes instituciones españolas, sus elementos y estructuras ornamentales, técnicas de decoración en las tapas, lomos y cortes, lo que sin duda nos apoya en la construcción de un corpus de elementos decorativos en encuadernaciones mudéjares y conocer la ubicación y su estado de conservación dentro de las instituciones.

Agradecimientos

El trabajo ha sido realizado gracias a la financiación concedida al Grupo Bibliopegia, grupo de investigación sobre encuadernación y el libro antiguo

(941369) por la Universidad Complutense de Madrid (GR29/20), y forma parte de los estudios que se han llevado a cabo sobre las encuadernaciones de la Biblioteca de la Casa de Alba. El proyecto se inició en 2013 con la firma de un convenio de colaboración entre la Fundación Casa de Alba y el Grupo Bibliopegia, donde se encuadra este trabajo sobre el estudio de las encuadernaciones de los Morales sobre el libro de Job de san Gregorio.

El estudio que presentamos es continuación de otros proyectos de catalogación de encuadernaciones mudéjares ya realizados, desarrollados en la Biblioteca Histórica de la UCM (2004), en la Catedral de Toledo (2007-2008), en la Real Academia de la Historia (2012-2015), y en la Biblioteca Nacional de España (2013).

Agradecemos al profesor José Manuel Calderón, responsable del Archivo, todas las facilidades y ayuda para el estudio y digitalización de las encuadernaciones de la Biblioteca.

\section{REFERENCIAS}

Avenoza, Gemma. 2008. "Las traducciones de la Biblia en castellano en la Edad Media y sus comentarios", en La Biblia en la Literatura Española. I/2 El texto: fuente y autoridad, coordinado por Gregorio del Olmo Lete y María Isabel Toro Pascua, 13-75. Madrid: Editorial Trotta.

Avenoza, Gemma. 2010. "Traducciones, público y mecenazgo (Castilla, siglo XV)". Romania 128: 452-500.

Avenoza, Gemma. 2011. Biblias castellanas medievales. Logroño: CILENGUA-Fundación San Millán de la Cogolla.

Avenoza, Gemma. 2014. "Volver a un archivo nunca es perder el tiempo: otro manuscrito medieval identificado en el Archivo Ducal de Alba (Mss 71, Morales de San Gregorio X-XVII)", en Vir bonus dicendi peritus: studies in honor of Charles B. Faulhaber, editado por Antonio Cortijo Ocaña, Ana M. Gómez Bravo y María Morrás, 1-15. New York: Hispanic Seminary of Medieval Studies.

Avenoza, Gemma. 2015. "Traducir y copiar la materia de Job en el siglo XV”, en Estudios de literatura medieval en la Península Ibérica, 267-278. San Millán de la Cogolla: Cilengua. Fundación de San Millán de la Cogolla. 
BNE (Biblioteca Nacional de España). 2013. Piel sobre tabla: Encuadernaciones mudéjares en la BNE. Madrid: BNE. Catálogo de la exposición, BNE, del 12 de marzo al 19 de mayo de 2013.

Bustos Táuler, Álvaro y Rebeca Sanmartín Bastida. 2016. "Fadrique Álvarez de Toledo, II Duque de Alba y su inventario de libros (1531): Una biblioteca patrimonial". Revista General de Información y Documentación 26 (1): 273-290.

Calderón Ortega, José Manuel. 2005. El ducado de Alba: la evolución histórica, el gobierno y la hacienda de un estado señorial (siglos XIV-XVI). Madrid: Dykinson.

Carpallo Bautista, Antonio. 2009. "Estudio de las encuadernaciones del siglo XV de la Biblioteca Complutense". Gutenberg Jabrbuch 2009: 315-355.

Carpallo Bautista, Antonio. 2012. "Las encuadernaciones mudéjares toledanas con motivo central de la catedral de Toledo". Anuario de Estudios Medievales 42 (2): 567-599.

Carpallo Bautista, Antonio y Esther Burgos Bordonau. 2012a. "Las encuadernaciones mudéjares de lacerías, tipo toledano y salmantino, en la Catedral de Toledo”. Al-Qantara 33 (2): 271-300.

Carpallo Bautista, Antonio y Esther Burgos Bordonau. 2012b. "Las encuadernaciones mudéjares de lacerías con motivos centrales en la Catedral de Toledo". Anales de Documentación 15 (1): 1-30.

Fuentes, Juan y Gemma Avenoza. 2012-2013. “La traducción castellana de los Moralia in Job atribuida a Pero López de Ayala: edición del 'Prólogo de san Gregorio que enbio a san Leandro, arçobispo de Seuilla' (BNM mss/10136 fols. 1v-4r)”. Incipit 32-33: 249-268.

Gonzalo Sánchez-Molero, José Luis. 2013. "La pervivencia en el siglo XVI del estilo mudéjar o 'pie de moro' en España”, en Piel sobre tabla. Encuadernaciones mudéjares en la BNE, 101-112. Madrid: BNE.

Hueso Rolland, Francisco. 1934. Exposición de encuadernaciones españolas: siglos XII al XIX. Madrid: Sociedad Española de Amigos del País.

López Serrano, Matilde y Francisco Tolsada. 1952. Exposición Histórica del libro Español de 1952. Madrid: Tipográfica Moderna.

Ruíz de Elvira, Isabel. 1993. "Encuadernaciones mudéjares de la Catedral de Segovia”, en XVIII Congreso Internacional de Bibliofilia, 1-5. Madrid, España, 20-24 de septiembre de 1993.

Serrano, Luciano. 1911. "Traducciones castellanas de los Morales de San Gregorio". Revista de Archivos, Bibliotecas y Museos 25:389-400.

Universidad de Valencia. 2003. Els vestits del saber: enquadernacions mudéjars a la Universitat de València. Valencia: Universitat.

Para citar este texto:

Carpallo Bautista, Antonio y José Luis Gonzalo Sánchez-Molero. 2022. "Las encuadernaciones mudéjares de los Morales de san Gregorio de la Biblioteca Nacional de España”. Investigación Bibliotecológica: archivonomía, bibliotecología e información 36 (90): 101-118.

http://dx.doi.org/10.22201/iibi.24488321xe.2022.90.58461 